\title{
Changes of health related quality of life during pregnancy based on pregnancy context: a prospective study
}

\author{
Ashraf Kazemi ${ }^{1,2^{*}}$, Aazam Dadkhah ${ }^{3}$ and Fatemeh Torabi ${ }^{1}$
}

\begin{abstract}
Background: The significance of planned pregnancy is an accepted principle for improving the health of pregnant women; and quality of life, as one of the important indicators of women's health, is reduced in high-risk pregnancies. The aim of this research was to investigate the changes in the health related quality of life (HRQL) in low risk pregnancies in different groups based on pregnancy context.

Methods: The present study was a prospective study conducted on 250 pregnant women divided into three groups of women with planned pregnancy, unplanned/wanted pregnancy and unwanted pregnancy. Then, using WHOQOL-26 questionnaire, the quality of life of these women was measured in physical, psychological, social and environmental dimensions at the beginning of pregnancy as well as at the end of the first, second and third trimesters.

Results: Based on the results, the mean score of environmental-HRQL in women with unwanted pregnancy was significantly lower than the other two groups. All dimensions on HRQL were influenced by time and group. However, changes in the physical, psychological and social dimensions of HRQL varied within the groups. Physical- HRQL changes were different within the groups. The intergroup effect on environmental dimension of quality of life changes was significant.
\end{abstract}

Conclusions: It was observed in this study that HRQL in the women with unwanted pregnancy was lower than the women with planned pregnancy and those with unplanned /wanted pregnancy. Moreover, increase in gestational age would lower quality of life, but this decline had a similar pattern in different groups.

Keywords: Pregnancy, Health Related Quality of Life, Low risk pregnancy, Pregnancy, Family Planning, Unwanted pregnancy

\section{Background}

Pregnancy is a complex period in women's lives. It is associated with significant physical and psychological changes that play an important role in balancing the functions of different systems in women's body with regard to the needs of the fetus. Although necessary for the survival of the fetus and the adaptation of the

\footnotetext{
* Correspondence: Kazemi@nm.mui.ac.ir

${ }^{1}$ Nursing and Midwifery Care Research Center, School of Nursing and Midwifery, Isfahan University of Medical Sciences, Isfahan, Iran

${ }^{2}$ Reproductive Health Department, School of Nursing and Midwifery, Isfahan University of Medical Sciences, Hezarjerib AV, Isfahan, Iran

Full list of author information is available at the end of the article
}

mother's body to new conditions, these changes make pregnant women vulnerable to physical and mental problems [1]. Additionally, these changes in various stages of pregnancy are associated with common complaints such as morning sickness, low back pain [2], movement restriction, Pelvic Girdle Pain [3] and sleep disorder [4]. Although these transient problems can be tolerated by most pregnant women and do not seriously threaten their health, they reduce the quality of life of these women during pregnancy [1].

Quality of life is an important criterion in evaluating development indicators. While health is defined as

C C The Author(s). 2022 Open Access This article is licensed under a Creative Commons Attribution 4.0 International License, which permits use, sharing, adaptation, distribution and reproduction in any medium or format, as long as you give appropriate credit to the original author(s) and the source, provide a link to the Creative Commons licence, and indicate if changes were made. The images or other third party material in this article are included in the article's Creative Commons licence, unless indicated otherwise in a credit line to the material. If material is not included in the article's Creative Commons licence and your intended use is not permitted by statutory regulation or exceeds the permitted use, you will need to obtain permission directly from the copyright holder. To view a copy of this licence, visit http://creativecommons.org/licenses/by/4.0/ The Creative Commons Public Domain Dedication waiver (http://creativecommons.org/publicdomain/zero/1.0/) applies to the data made available in this article, unless otherwise stated in a credit line to the data. 
complete physical, psychological, and social well-being, quality of life is a mental perception of health [5] affected by illnesses as well as physical [6] and mental [7]. High-risk and complicated pregnancies are among the factors affecting the decline of the HRQL in pregnant women [8]. Nonetheless, change in HRQL in low risk pregnancies have received less attention. Moreover, due to the mental nature of quality of life, it can be influenced by different aspects of life. So that pregnancy complications such as hyperemesis have increased drastically after unwanted and unplanned pregnancies [9]. There are also studies reporting the low trend in HRQL following an unplanned pregnancy [10]. Although physical and psychological changes of pregnancy and the complications caused by them occur for most women, their impact on quality of life may be influenced by women's preparation and planning for pregnancy.

Planned pregnancy is one of the major goals of reproductive health whose desirability is an accepted principle in family planning as well as maternal and child health [4]. Denial of pregnancy following an unplanned pregnancy may reduce a person's psychological tolerance to pregnancy changes.

As the results of a qualitative study showed, couples defined planned pregnancy as adaptation to the conditions of having a child. Common problems in pregnancy such as pelvic girdle pain [11] and low back pain [12] and body dissatisfaction [13] may reduce the quality of life of pregnant women. Accordingly, family planning for childbearing provides the couples with the necessary readiness to accept pregnancy, and may reduce the negative effects of pregnancy on quality of life. However, it should be noted that even unplanned pregnancy can also be associated with pregnancy acceptance [14] and lessen the negative effects of unplanned pregnancy on the HRQL of pregnant women. In addition, the impact of unplanned and unwanted pregnancies on HRQL can be subject to the cultural beliefs and values governing different societies.

The impossibility of legal abortion because of religious values in some societies increases the likelihood of continuing unplanned and unwanted pregnancies. As such, understanding the changes in quality of life during unplanned and unwanted pregnancies seems to be essential in these societies. Accordingly, this study investigated change in HRQL of pregnant women in terms of pregnancy context $(\mathrm{PC})$.

\section{Method}

This prospective study, approved by the Ethics Committee of Isfahan University of Medical Sciences, was conducted between April 2017 and January 2018 in IsfahanIran. Taking into account the $95 \%$ confidence level, the level of significance $(\alpha), 0.05(Z \alpha / 2=1.96)$, the power
$80 \%$ and the maximum acceptable error in estimating the comparison of principal variables 0.7 and the variance of depressive changes $\left(\partial:^{2}=7\right)$ the sample size was calculated 250 women. The study was conducted on 250 women with gestational age of 6-9 weeks who referred to ten Health Centers in Isfahan to start prenatal care. Based on the weekly number of clients in each center, between 20 and 30 samples were considered. Inclusion criteria were aged between 18 and 35 years, no history of complications in previous pregnancies, no systemic disease in current pregnancy, and no known prepregnancy psychological disorder. Exclusion criteria were including twin or multiple pregnancy diagnosis and abortion in the first trimester, pregnancy complications such as preeclampsia and second trimester pregnancy bleeding, and stressful events such as death of relatives, economic bankruptcy and suchlike.

The centers were selected from two networks in Isfahan using stratified random cluster sampling. and the pregnant women were selected by convenience sampling method and all eligible pregnant women were invited to participate in the study and, after obtaining informed consent, their demographic data were recorded.

To determine PC, intention and wantedness for pregnancy were asked about using interview and those who were pregnant with a pre-planned program were put into the planned pregnancy group, those who were pregnant without a predetermined program but wanted the baby, were put into the unplanned/wanted group and, finally, those who became pregnant without a predetermined program and did not want the baby were placed in the unwanted pregnancy group [14].

The subjects' HRQL was measured using WHO Quality of Life-BREF (WHOQL-26) at 11-12 (T1), 24-25 (T2) and 33-35 weeks (T3) of pregnancy (4) .

The validated WHOQL-26 is a self-reported survey that consists of 26 questions regarding quality of life and is divided into four domains physical health (7 items), psychological health (6 items), social relationships (3 items), and environmental health (8 items). This questionnaire was performed on a 5-point Likert scale (strongly agree: 5 score to strongly disagree: 1 score). The scores of each domain and also total score were transformed linearly to a $0-100$-scale [15]. The questionnaires were completed by women.

\section{Statistical analysis}

Data analysis was performed using IBM SPSS 19 software (SPSS Inc., Chicago, IL, USA). Normal distribution assumption was tested by the Kolmogorov-Smirnov test. Since, the HRQL and its domains score were normally distributed; parametric statistics were applied for the data analysis. Baseline characterizes were compared between three groups of women, based on PC using 
analysis of variance (for age), Chi-square (for employment status) and Mann-Whitney $U$ test (for education and gravity) The mean scores' differences of dependent variables in T1, T2 and T3 between three groups of women, based on PC were evaluated using analysis of covariance (ANCOVA), controlling for baseline data and independent variables (group as fixed parameter and mean scores of the HRQL and its domains at T1 as covariate). The variables women's age, educational level, gravidity and employment status were considered as potential confounders and were compared in three groups of PC. Variables that were different between the three groups were entered in the models. Repeated measure analysis of variance (RMANOVA) was used to assess the changes in HRQL during the study follow-ups. Also women education as potential confounder was entered in the models.

\section{Results}

Of the 370 women invited to participate in the study, 300 accepted to take part in it. 29 pregnant women because of abortion and 21 others because of pregnancy complications such as preeclampsia, bleeding in the second trimester, and preterm labor pain were excluded from the study. Then, the data of 250 pregnant women aged between 18 and 35 years old were analyzed. Among these women, 153 women (61.2\%) had planned pregnancy, 72 women (28.8\%) unplanned/ wanted pregnancy, and 25 women (10\%) had unwanted pregnancy (Fig. 1).

Based on the results, the three groups were not different in terms of age, gravidity, employment status. However, the frequency of under-diploma education level in the unwanted and unplanned pregnancy groups was higher than that of the planned pregnancy group (Table 1). Therefore. women's education was entered in the models as covariant variable.

The mean score of the physical, psychological and environmental HRQL at T1 in women with unwanted pregnancy were lower than the other groups. The results of the ANCOVA test with controlling education level and dimensions of HRQ at T1, showed that, adjusted to the education level, the mean score of all dimensions of HRQL at T2 and T3 were different between groups (Table 2). The mean score of the dimensions of HRQ in planned/ wanted and unplanned/ wanted group decreased at T2 and T3; however, these variables in the women with unwanted pregnancy were lower and more stable.

The results of RMANOVA showed that the interaction effect of time and education level on physical, psychological and environmental HRQL and also, interaction effect of time and PC on physical HRQL were significant (Table 3). The effect of education $(\mathrm{F}=13.7, P<.001)$ and

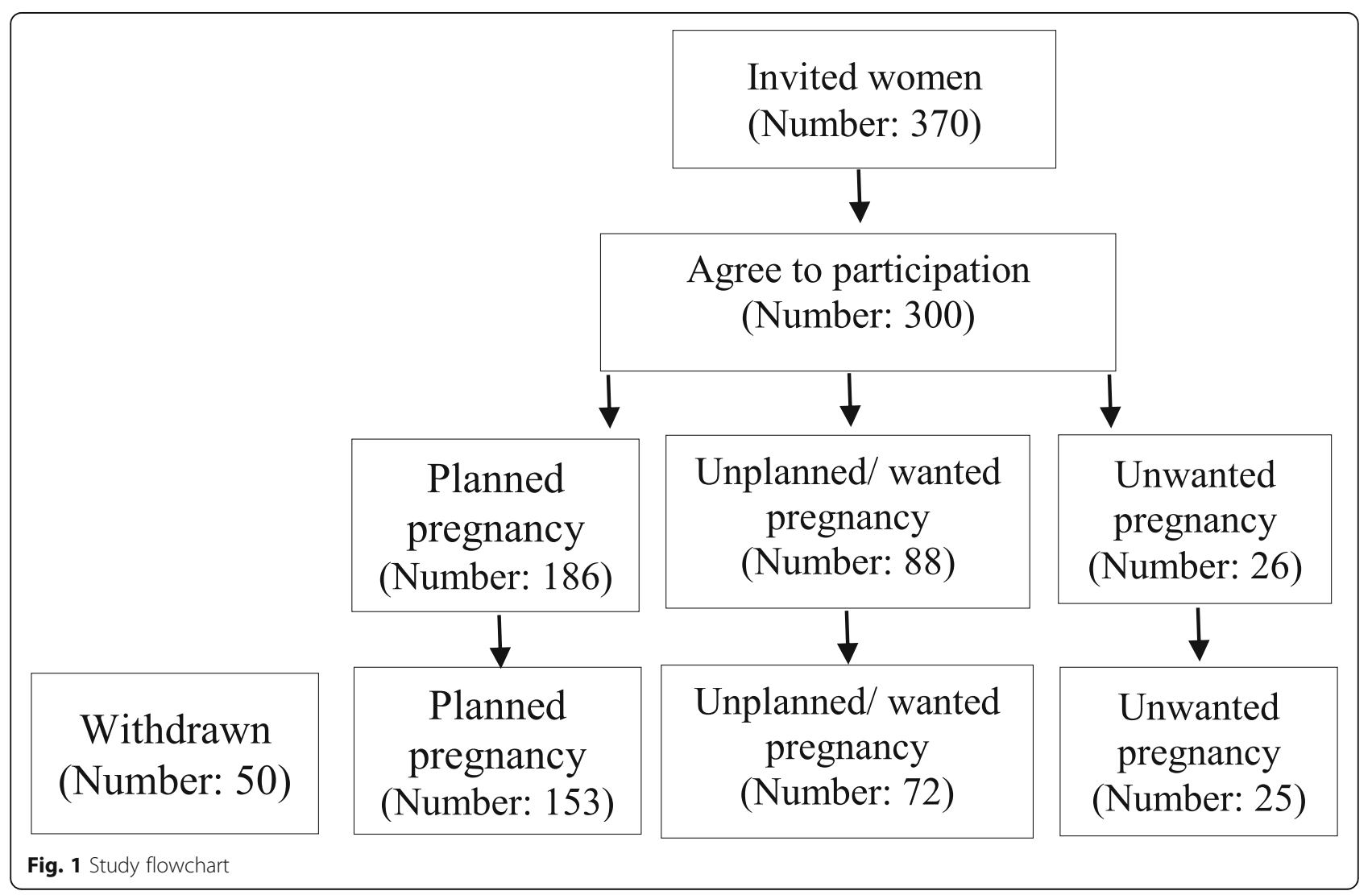


Table 1 The baseline characteristics of the subjects

\begin{tabular}{|c|c|c|c|c|}
\hline \multirow[b]{2}{*}{ Groups } & \multicolumn{3}{|c|}{ Mean (standard deviation) or Number (\%) } & \multirow[t]{3}{*}{ Sig } \\
\hline & Wanted/ Planned & Wanted /Unplanned & Unwanted & \\
\hline Number & 153 & 72 & 25 & \\
\hline Age & $28.7(3.9)$ & $29.0(4.6)$ & $28.6(3.7)$ & 0.84 \\
\hline Gravity & $1.5(0.8)$ & $1.39(0.6)$ & $1.83(0.9)$ & 0.09 \\
\hline Education(\%) & & & & 0.001 \\
\hline High school & $13(8.5)$ & $8(11.1)$ & $3(12.0)$ & \\
\hline Diploma & $69(45.1)$ & $23(31.9)$ & $13(52.0)$ & \\
\hline Academic & $71(46.4)$ & $41(56.9)$ & $9(36.0)$ & \\
\hline Occupation (\%) & & & & 0.10 \\
\hline Employed & $22(8.8)$ & $9(5.9)$ & $9(12.5)$ & \\
\hline
\end{tabular}

Rials (R): Eeach dollar equal to 45000 Rails at the of data gendering time in this study

PC $(\mathrm{F}=5.07, P=.007)$ on mean score of the environmental HRQL were significant (tests of between subjects' effects).

\section{Discussion}

This study aimed at investigating the change in HRQL during uncomplicated pregnancies with regard to PC. To this end, the quality of life changes were compared between three groups of pregnancy context; women with planned, unplanned/wanted and unplanned/unwanted pregnancies. The results showed that HRQL had a decreasing from the beginning of pregnancy to the third trimester. Although women with planned pregnancies have a higher quality of life with the onset of pregnancy, they experience similar changes compared to the other two groups.

Comparing the background characteristics of the groups, it was shown that the frequency of underdiploma education level in women with planned pregnancy was lower than the other two groups. This finding corroborates the results of other studies indicating that women's education is a determining factor in family planning [16, 17]. Nevertheless, unlike other studies [18-20], it was not a determining factor in quality of life. Additionally, contrary to the results of other studies [21, $22]$, the results of the present study demonstrated that number of pregnancies, and age were not related to planning for pregnancy.

Evaluation of change in HRQL over four periods of time confirmed the effect of time on the total quality of life score and its different dimensions. So that the HRQL score decreased during the first trimester, then, remained stable during the second trimester and, finally, began to decrease again after the second and during the third trimesters. This change was consistent with the situation of pregnant women during different pregnancy periods. Common problems in the 1th trimester, such as morning sickness [23], lead to lower HRQL in this trimester.

In the second trimester, decrease in this sickness often results in fewer problems for women, explaining how quality of life does not change during the second trimester. Increased prevalence of pregnancy problems following an increase in abdominal enlargement, restriction of movement and sleep disorder during this period [24] is

Table 2 Comparison of health related quality of life domains mean scores between the groups

\begin{tabular}{|c|c|c|c|c|c|c|c|c|c|c|c|c|c|c|c|}
\hline \multirow[b]{3}{*}{ HQOL } & \multirow{2}{*}{\multicolumn{3}{|c|}{$\begin{array}{l}\text { Time } 1 \\
\text { Mean } \\
\text { (SD) }\end{array}$}} & \multirow{2}{*}{\multicolumn{3}{|c|}{$\begin{array}{l}\text { Time } 2 \\
\text { Mean } \\
\text { (SD) }\end{array}$}} & \multirow{2}{*}{\multicolumn{3}{|c|}{ Statistical results }} & \multirow{2}{*}{\multicolumn{3}{|c|}{$\begin{array}{l}\text { Time } 3 \\
\text { Mean } \\
\text { (SD) }\end{array}$}} & \multirow{2}{*}{\multicolumn{3}{|c|}{ Statistical results }} \\
\hline & & & & & & & & & & & & & & & \\
\hline & G1 & G2 & G3 & G1 & G2 & G3 & $F^{h}$ & $P^{h}$ & $n p^{2 h}$ & G1 & G2 & G3 & $\mathrm{F}^{\mathrm{h}}$ & $P^{h}$ & $n p^{2 h}$ \\
\hline Physical & $\begin{array}{l}27.3 \\
(3.9)\end{array}$ & $\begin{array}{l}27.1 \\
(3.9)\end{array}$ & $\begin{array}{l}23.3 \\
(3.5)\end{array}$ & $\begin{array}{l}23.7 \\
(5.3)\end{array}$ & $\begin{array}{l}23.4 \\
(4.5)\end{array}$ & $\begin{array}{l}24.0 \\
(6.1)\end{array}$ & 95.0 & $<0.001$ & 0.29 & $\begin{array}{l}24.3 \\
(3.7)\end{array}$ & $\begin{array}{l}24.2 \\
(4.3)\end{array}$ & $\begin{array}{l}23.8 \\
(3.8)\end{array}$ & 146.8 & $<0.001$ & 0.38 \\
\hline Psychological & $\begin{array}{l}23.3 \\
(3.1)\end{array}$ & $\begin{array}{l}22.6 \\
(3.3)\end{array}$ & $\begin{array}{l}21.3 \\
(3.7)\end{array}$ & $\begin{array}{l}20.5 \\
(4.1)\end{array}$ & $\begin{array}{l}20.1 \\
(4.0)\end{array}$ & $\begin{array}{l}20.0 \\
(4.1)\end{array}$ & 132.5 & $<0.001$ & 0.35 & $\begin{array}{l}21.1 \\
(3.5)\end{array}$ & $\begin{array}{l}20.3 \\
(3.6)\end{array}$ & $\begin{array}{l}20.0 \\
(3.6)\end{array}$ & 152.5 & $<0.001$ & 0.39 \\
\hline Social & $\begin{array}{l}12.1 \\
(1.5)\end{array}$ & $\begin{array}{l}12.0 \\
(1.3)\end{array}$ & $\begin{array}{l}11.7 \\
(1.4)\end{array}$ & $\begin{array}{l}10.6 \\
(2.1)\end{array}$ & $\begin{array}{l}10.6 \\
(2.2)\end{array}$ & $\begin{array}{l}10.8 \\
(1.9)\end{array}$ & 61.8 & $<0.001$ & 0.20 & $\begin{array}{l}11.1 \\
(2.1)\end{array}$ & $\begin{array}{l}10.7 \\
(2.0)\end{array}$ & $\begin{array}{l}10.9 \\
(1.9)\end{array}$ & 79.9 & $<0.001$ & 0.25 \\
\hline Environmental & $\begin{array}{l}30.4 \\
(3.5)\end{array}$ & $\begin{array}{l}29.1 \\
(3.3)\end{array}$ & $\begin{array}{l}28.9 \\
(3.8)\end{array}$ & $\begin{array}{l}28.9 \\
(3.9)\end{array}$ & $\begin{array}{l}27.5 \\
(4.4)\end{array}$ & $\begin{array}{l}27.5 \\
(3.2)\end{array}$ & 248.2 & $<0.001$ & 0.50 & $\begin{array}{l}29.9 \\
(3.9)\end{array}$ & $\begin{array}{l}27.8 \\
(3.8)\end{array}$ & $\begin{array}{l}28.1 \\
(4.3)\end{array}$ & 233.4 & $<0.001$ & 0.49 \\
\hline
\end{tabular}

Abbreviations: G1: Planned pregnancy; G2: Unplanned/ Wanted pregnancy; G3: Unplanned/ unwanted pregnancy; HQOL: health related quality of life; SD = Standard deviation, $\mathrm{np} 2=$ partial eta-squared 
Table 3 Differences in the HRQOL at the three assessing times (repeated measure analysis of variance)

\begin{tabular}{|c|c|c|c|c|c|c|c|}
\hline & \multicolumn{3}{|c|}{ Mean (standard deviation) } & \multicolumn{2}{|c|}{ Time/ Group } & \multicolumn{2}{|c|}{ Time/ Education } \\
\hline & Time 1 & Time 2 & Time 3 & $F^{a}$ & $\mathrm{Sig}^{\mathrm{a}}$ & $F^{a}$ & $\mathrm{Sig}^{\mathrm{a}}$ \\
\hline Total HRQOL & $91.8(10.2)$ & $83.2(12.8)$ & $61.51(16.0)$ & 1.1 & 0.33 & 4.7 & 0.009 \\
\hline Physical HRQOL & $27.0(3.9)$ & $23.9(4.9)$ & $24.1(4.5)$ & 2.7 & 0.02 & 6.3 & 0.002 \\
\hline Psychological HRQOL & $12.0(1.5)$ & $10.6(2.1)$ & $20.6(3.6)$ & 1.2 & 0.37 & 8.7 & $<0.001$ \\
\hline Social HRQOL & $22.9(3.3)$ & $20.3(4.1)$ & $11.0(2.1)$ & 1.1 & 0.55 & 2.1 & 0.08 \\
\hline Environmental HRQOL & $29.8(3.6)$ & $28.3(4.1)$ & $28.6(3.9)$ & 0.2 & 0.97 & 3.5 & 0.03 \\
\hline
\end{tabular}

Abbreviations: HRQOL: Health related Quality of Life; ${ }^{a}$ test of between subject effect; $n$ s: non-significant

also associated with decreased quality of life. Decreased quality of life associated with the increase of gestational age has been reported previously [17], and the present study attempted to show that this change occurs even during uncomplicated pregnancies Als, a study on Chinese women pregnant showed an increase in quality of life in the second trimester of pregnancy. In this study, the quality of life in the third trimester had been reported at the lowest level [25].

In line with the main objectives of this research, the results suggested that, from the outset of pregnancy, women in the unwanted pregnancy group reported lower quality of life compared to the other two groups; moreover, throughout the pregnancy, their quality of life in the environmental dimension was lower than the other two groups. Changes in overall quality of life and quality of life in physical, psychological and social dimensions followed the same pattern in all three groups. This finding suggests that, except for the environmental dimension of quality of life, other aspects are less affected by unwanted pregnancy during pregnancy; while this factor (unwanted pregnancy) has an ever-lasting impact on the environmental dimension of HRQL.

As previous studies have shown, unwanted and unplanned pregnancies can reduce quality of life in women [20]. Nonetheless, no difference was observed in the present study in the quality of life of the women with planned pregnancy and those with unplanned/wanted pregnancy. According to this finding, the wantedness of the pregnancy in the women of the study, even if not based on previous planning, does not have an adverse effect on the quality of life of these women. By contrast, unwanted pregnancy can reduce the quality of life of pregnant women.

Providing physical, psychological, social and environmental facilities is one of the conditions considered by people judging the timeliness of pregnancy. Put differently, a pregnancy is considered timely when it occurs in an appropriate condition. The environmental dimension of quality of life refers to the availability of environmental and supportive facilities [4] and, it should be noted, that differences between groups are expected at the beginning of pregnancy. But it was observed unexpectedly within the first trimester, that women with planned pregnancies experienced more decrease in the environmental dimension than women with unplanned/wanted pregnancies.

Decreased environmental quality of life during the second trimester for the women with planned and wanted pregnancies is maybe due to an incorrect estimation of conditions for planning the pregnancy. Furthermore, although perceived social support has not been measured in this study, decreased environmental quality of life in this women suggests that the available support systems have failed to decrease the problems of women during the first trimester.

One of the limitations of the present study, that needs to be taken into account in interpreting the results, is that poor pre-pregnancy quality of life can be a reason for women's unwillingness to become pregnant. Therefore, to identify the causal pathway between PC and quality of life, the pre-pregnancy quality of life of these women needs to be assessed. In addition, the low number of women with unwanted pregnancies is another limitation of the study that may affect the results of the study.

\section{Conclusions}

The results of this study showed that the increase of gestational age can reduce the quality of life in uncomplicated pregnancies. It was also shown that based on PC there is a similar pattern of change in physical, psychological and social dimensions of quality of life in different groups of women. However, the environmental dimension of quality of life in women with unwanted pregnancies is lower than other groups and, hence, needs to be taken into account in planning pregnancy cares for these women.

\section{Abbreviations \\ HRQL: health related quality of life; PC: pregnancy context; T: Time; \\ ANCOVA: analysis of covariance; RMANOVA: repeated measures analysis of variance; G: group; np2: partial eta-squared}

\section{Acknowledgements}

The authors gratefully acknowledge the Institutional Review Board affiliated with Isfahan University of Medical Sciences that supported financially this research project. 


\section{Authors' contributions}

AD carried out the project development, data Collection. AK carried out the project development, data collection supervising, acquisition of analysis, interpretation of data and writing and editing the manuscript. FT carried out the data collection supervising, acquisition of analysis. The author(s) read and approved the final manuscript.

\section{Funding}

This study was funded by Isfahan University of Medical Sciences (Grant number: 396367).

\section{Availability of data and materials}

Data and material are available on request from the corresponding author.

\section{Declarations}

\section{Ethics approval and consent to participate}

All procedures performed in participants were in accordance with the ethical standards of the Isfahan University of Medical Sciences and informed consent was obtained from all participants.

\section{Consent for publication}

No applicable.

\section{Competing interests}

The authors declare that they have no conflict of interest.

\section{Author details}

${ }^{1}$ Nursing and Midwifery Care Research Center, School of Nursing and Midwifery, Isfahan University of Medical Sciences, Isfahan, Iran. ${ }^{2}$ Reproductive Health Department, School of Nursing and Midwifery, Isfahan University of Medical Sciences, Hezarjerib AV, Isfahan, Iran. ${ }^{3}$ Student Research Committee, School of Nursing \& Midwifery, Isfahan University of Medical Sciences, Isfahan, Iran.

Received: 13 October 2021 Accepted: 13 January 2022

Published online: 21 January 2022

\section{References}

1. Royal College of Obstetricians and Gynaecologists. Report of the RCOG Working Party on Unplanned Pregnancy. London, Royal College of Obstetricians and Gynaecologists.1991.

2. Backhausen MG, Bendix JM, Damm P, Tabor A, Hegaard HK. Low back pain intensity among childbearing women and associated predictors. A cohort study. Women Birth. 2019;32:E467-76.

3. Vermani E, Mittal R, Weeks A. Pelvic girdle pain and low back pain in pregnancy: a review. Pain Pract. 2010;10:60-71.

4. Balserak BI, Lee K. Sleep disturbances and sleep-realted disorders in pregnancy. In: Kryger MH, Roth T, Dement WC, editors. Principles and practice of sleep medicine. Elsevier Saunders; 2011. pp. 1572-86.

5. Karimi M, Brazier J. Health, Health-Related Quality of Life, and Quality of Life: What is the Difference? Pharmacoeconomics. 2016;34:645-9.

6. Rezaei N, Azadi A, Zargousi R, Sadoughi Z, Tavalaee Z, Rezayati M. Maternal Health-Related Quality of Life and Its Predicting Factors in the Postpartum Period in Iran. Scientifica. 2016;2016:8542147.

7. Sogaard HJ, Bech P. The effect of detecting undetected common mental disorders on psychological distress and quality of life in longterm sickness absence: a randomised controlled trial. Scand I Public Health. 2010:38:845-56.

8. Saadati F, Sehhatiei Shafaei F, Mirghafourvand M. Sleep quality and its relationship with quality of life among high-risk pregnant women (gestational diabetes and hypertension). J Matern Fetal Neonatal Med. 2018; 31:150-7.

9. Goossens J, Van Den Branden Y, Van der Sluys L, Delbaere I, Van Hecke A, Verhaeghe $S$, et al. The prevalence of unplanned pregnancy ending in birth, associated factors, and health outcomes. Hum Reprod. 2016:31:2821-33.

10. Jamali S, Pournowrooz N, Alborzi M, Imanian M, Mosallanzhad Z. Comparison Quality of Life in Women with Wanted and Unwanted Pregnancy and Associated Factors: A study from Iran. IJBR. 2018;9:13-8.

11. 11. Mackenzie J, Murray E, Lusher J. Women's experiences of pregnancy related pelvic girdle pain: A systematic review. Midwifery. 2018; 56: 102-11.
12. 12. Berber MA, Satılmış IG. Characteristics of Low Back Pain in Pregnancy, Risk Factors, and Its Effects on Quality of Life. Pain Manag Nurs. 2020; 21(6): $579-86$.

13. 13. Riquin E, Lamas C, Nicolas I, Dugre Lebigre C, Curt F, Cohen H, Legendre G, Corcos M, Godart N. A key for perinatal depression early diagnosis: The body dissatisfaction. J Affect Disord. 2019;15; 245: 340-7.

14. Barrett $\mathrm{G}$, Wellings $\mathrm{K}$. What is a 'planned' pregnancy? Empirical data from a British study. Soc Sci Med. 2002;55:545-57.

15. Yousefy AR, Ghassemi GR, Sarrafzadegan N, Mallik S, Baghaei AM, Rabiei K. Psychometric properties of the WHOQOL-BREF in an Iranian adult sample. Community Ment Health J. 2010:46:139-47.

16. Hall JA, Barrett G, Phiri T, Copas A, Malata A, Stephenson J. Prevalence and Determinants of Unintended Pregnancy in Mchinji District, Malawi; Using a Conceptual Hierarchy to Inform Analysis. PLoS One. 2016;11:e0165621.

17. Lagadec N, Steinecker M, Kapassi A, Magnier AM, Chastang J, Robert S, et al. Factors influencing the quality of life of pregnant women: a systematic review. BMC Pregnancy Childbirth. 2018;18:455.

18. Shams L, Tajik M, Heidari P, Nasiri T, Mohammadshahi M. Quality of life of Iranian and Afghan pregnant women in rural Iran. Ann Ig. 2022;34:70-8.

19. Lundsberg LS, Xu X, Schwarz EB, Gariepy AM. Measuring health utility in varying pregnancy contexts among a diverse cohort of pregnant women. Contraception. 2017:96:411-9.

20. Ali A. Relationship between Unwanted Pregnancy and Health-Related Quality of Life in Pregnant Women. J Coll Physicians Surg Pak. 2016;26: 507-12.

21. Acharya P, Gautam R, Aro AR. Factors influencing mistimed and unwanted pregnancies among Nepali women. J Biosoc Sci. 2016;48:249-66.

22. Koren A, Mawn B. The context of unintended pregnancy among married women in the USA. J Fam Plann Reprod Health Care. 2010;36:150-8.

23. Tan A, Lowe S, Henry A. Nausea and vomiting of pregnancy: Effects on quality of life and day-to-day function. Aust N Z J Obstet Gynaecol. 2018;58: 278-90.

24. Sut HK, Asci O, Topac N. Sleep Quality and Health-Related Quality of Life in Pregnancy. J Perinat Neonatal Nurs. 2016;30:302-9.

25. Wu H, Sun W, Chen H, Wu Y, Ding W, Liang S, Huang X, Chen H, Zeng Q, Li Z, Xiong P, Huang J, Akinwunmi B, Zhang CJP, Ming WK. Health-related quality of life in different trimesters during pregnancy. Health Qual Life Outcomes. 2021;19(1):182.

\section{Publisher's Note}

Springer Nature remains neutral with regard to jurisdictional claims in published maps and institutional affiliations.

Ready to submit your research? Choose BMC and benefit from:

- fast, convenient online submission

- thorough peer review by experienced researchers in your field

- rapid publication on acceptance

- support for research data, including large and complex data types

- gold Open Access which fosters wider collaboration and increased citations

- maximum visibility for your research: over $100 \mathrm{M}$ website views per year

At $\mathrm{BMC}$, research is always in progress.

Learn more biomedcentral.com/submissions 